\title{
Inkarsere herni kesesi içinde perfore apandisit (Amyand hernisi): Olgu sunumu
}

\section{Perforated appendicitis in an incarcerated hernia sac (Amyand's hernia): A case report}

\author{
Uğur Abakay, Birkan Bozkurt*, Sinan Soylu, Meriç Emre Bostancı, Kürşat \\ Karadayı
}

Genel Cerrahi Anabilim Dalı (Dr. U. Abakay, Yrd. Doç. B. Bozkurt, Yrd. Doç. S. Soylu, Dr. M. E. Bostanc1, Prof. Dr. K. Karaday1), Cumhuriyet Üniversitesi Tıp Fakültesi, TR-58140 Sivas

\begin{abstract}
Özet
İnguinal herni kesesi içerisinde inflamasyon olsun yada olmasın apendiks vermiformis bulunması, Amyand herni olarak isimlendirilir. Amyand hernisi, inguinal herni olgularının yaklaşık \%1'i kadar görülür. Akut apendisitli olgularda ise Amyand herni sıklı̆̆ \%0,1 olarak bildirilmiştir. İnkarsere inguinal herni kliniği, çoğunlukla akut apandisitin belirti ve bulgularını maskeler ve bu nedenle preoperatif tanı koymak zor olabilir. Bu yazımızda, inkarsere inguinal herni nedeniyle acil opere edilen ve peroperatuvar herni kesesi içinde perfore apandisit saptanarak Amyand hernisi tanısı konan 81 yaşında erkek hasta olgusu sunulmuş ve ilgili literatürler eşliğinde tartışılmıştır.
\end{abstract}

Anahtar sözcükler: İngıinal herni, amyand hernisi, akut apandisit

\begin{abstract}
Amyand hernia is determined as the presence of normal or inflamed appendix in the hernia sac. Amyand's hernia is seen in approximately $1 \%$ of inguinal hernia cases. Incidance of Amyand's hernia is reported $0.1 \%$ in a case with acute appendisitis. Signs and symptoms of acute appendicitis are overshadowed by clinical findings related to incarcerated inguinal hernia and thus preoperative diagnosis of Amyand's hernia may be difficult. The aim of this report is to describe and review the litreture in a case 81 years old male patient operated for incarcerated inguinal hernia and diagnosed as Amyand hernia in peroperative period.
\end{abstract}

Keywords: Inguinal hernia, amyand's hernia, acute appendisitis

Geliş tarihi/Received: 17 Kasım 2014; Kabul tarihi/Accepted: 20 Aralık 2014

*iletişim adresi:

Dr. Birkan Bozkurt, Genel Cerrahi Anabilim Dalı, Cumhuriyet Üniversitesi Tip Fakültesi, TR58140 Sivas. E-posta: birkan.bozkurt@gmail.com

\section{Giriş}

İnguinal herni ve akut apandisit s1k görülen cerrahi hastalıklar olmasına rağmen birliktelikleri nadir görülür. Akut apendisitli olgularda ise Amyand hernisi sıklığ $1 \% 0,1$ olarak bildirilmiştir [1, 2]. Rene Jacques Croissantde Garengeotde 1731'defemoral herni kesesi içinde ilk akut apendisit olgusunu yayımlamıştır [3]. Kral II. George'un cerrahı olarak bilinen Claudius Amyand' in ise 1735'te Londra'da 11 yaşındaki bir erkek hastada fitık kesesi içerisinde perfore apendiks saptamış ve hastalığı literatüre bu isimle geçirmiştir [4]. Amyand hernisi, herni kesesi içinde, inflamasyon olsun yada olmasın apendiks vermiformisin bulunması olarak tanımlanır. Amyand hernisi'nin ameliyat öncesi tanısı oldukça güçtür. Hastalar genellikle inkarsere fitık tanısı ile ameliyata alınırlar $[3,5-7]$. 
$\mathrm{Bu}$ olgu sunumunda, Amyand hernisi olarak adlandırılan ve nadir görülen, inkarsere inguinal herni kesesi içinde perfore apandisit saptanan olgunun literatürler eşliğinde irdelenmesi amaçlanmıştır.

\section{Olgu sunumu}

Seksen bir yaşında erkek hasta, 1 aydır olan sağ kasıkta şişlik ve son 1 haftadır bu bölgede ağrı şikayeti ile acil servisimize başvurdu. Bulantı ve kusma tariflemeyen hastanın gaz gayta çıkışının mevcut olduğu öğrenildi. Fizik muayenesinde sağ inguinal bölgede redükte edilemeyen ağrılı kitle tespit edildi. Batın muayenesinde özellik yoktu. Özgeçmişinde geçirilmiş ameliyatı veya sistemik bir hastalığ ${ }_{1}$ yoktu. Hastanın tam kan sayımı ve biyokimyasal parametrelerinde özellik yoktu. Sağ inguinal bölgeye yönelik yapılan yüzeyel ultrasonografisinde, sağ inguinal kanal distaline herniye barsak ansları ve yağ planları izlendi ve herniye barsak anslarında dopler inceleme ile akım mevcuttu. Kontrastlı batın tomografisinde, sağ inguinal kanala herniye mezenterik yağ planları izlenmiş, ayrıca sağ inguinal kanalda yaklaşık $5 \times 5,5 \mathrm{~cm}$ boyutlarında heterojen kontrastlanan ve içerisinde çoğunlukla kistik alanların bulunduğu lezyon saptandı (Resim 1).

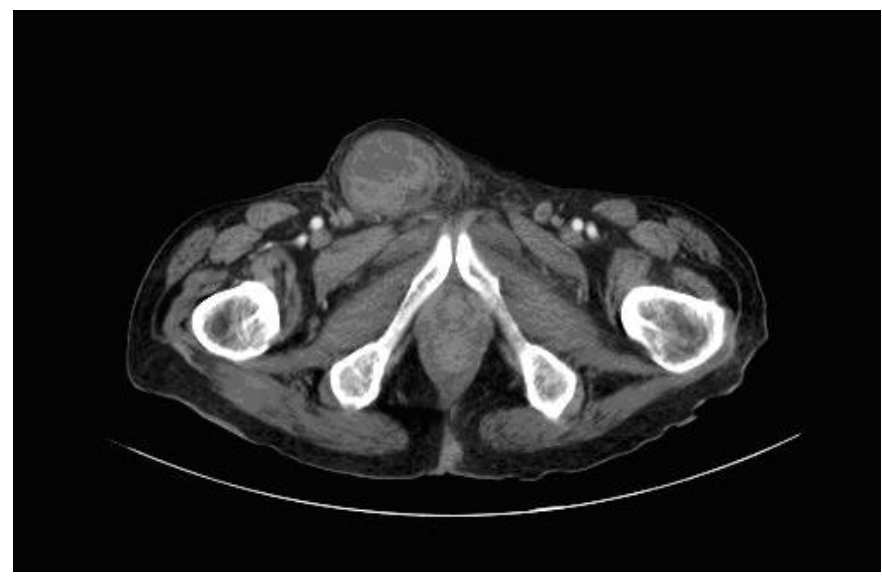

Resim 1. Bilgisayarlı abdominal tomografide sağ inguinal bölgede inkarsere herni.

Hasta acil şartlarda şartlarda operasyona aldındı. Sağ inguinal inzizyon ile herni kesesine ulaşıldı. Herni kesesi açıldığında pürülan mayinin geldiğini görüldü ve loj drene edilerek serum fizyolojik ile yıkandı. Explorasyon devamında, herni kesesi içinde apendiksin olduğu ve distalinden perfore olarak abse formasyonu oluşturduğunu tespit edildi (Resim 2). Apendektomi uygulandı ve çevre nekrotik dokuları debride edildi .Çekum tabanında ve komşu barsak duvarlarında herhangi bir patolojiye rastlanmadi. Enfeksiyon riskinden dolay1 prostetik materyal kullanmadan hastaya herniorafi uyguland 1 Postoperatif 3. gün herhangi bir komplikasyon gelişmeyen hasta taburcu edildi.

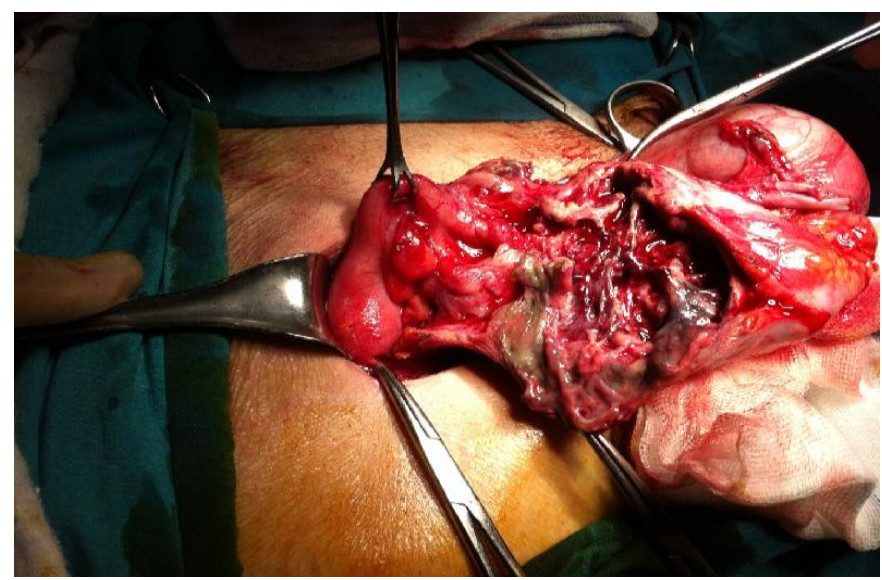

Resim 2. İnguinal herni kesesi içinde distalinden perfore apandisit. 


\section{Tartışma}

Herni, batın içindeki herhangi bir organın yer değiştirmesi sonucu meydana gelmiş olan batın duvarı defekti olarak tanımlanır. İnguinal herni ve akut apandisit sık görülen cerrahi hastalıklar olmasına rağmen birliktelikleri nadir görülür. İnkarsere inguinal herni ile birlikte inflame veya perfore apendisit varlığı ise çok nadir görülen bir durum olup tüm akut apandisitli olguların yaklaşık $\% 0,1$ 'ini oluşturmaktadır $[1,2]$. Apendiksin inguinal herni kesesi içinde bulunması Amyand herni olarak adlandırılmakta olup, ilk kez Claudius Amyand tarafindan 1735 tarihinde 11 yaşındaki bir erkek çocuğunda herni kesesi içerisinde perfore bir apendiks varlığının bulunmasıyla tanımlanmıştır [3, 4]. Bizim olgumuzda inguinal herni kesesi içerisinde perfore apendiks dokusu mevcuttu.

Herni kesesi içindeki apendiks varlığı genellikle fitık kesesi açıldıktan sonra tespit edilebilir [6, 8]. Bizim olgumuzda da tanı peroperatif konmuştur. Kontrastlı bilgisayarlı tomografi, inguinal herni tanısında rutin kullanımda olmamakla birlikte, girişim öncesinde tanı konmasında yardımcı olabilir [5, 9, 14]. Luchs ve ark. [10] ameliyat öncesinde tomografi ile tanı koydukları iki olgu bildirmişlerdir. Weber ve Kraal [11] 60 olguluk Amyand hernisi serisinde 1 hastada ameliyat öncesinde tanı koymuşlardır. Anagnostopoulou ve ark. [12] üç aylı bir erkek hastada ameliyat öncesinde ultrasonografi ile Amyand hernisi tanısı koyduklarını bildirmişlerdir. Bizim olgumuzda, kontrastlı batın tomografisinde, sağ inguinal kanala herniye mezenterik ya ̆ planları izlenmiş, ayrıca sağ inguinal kanalda yaklaşık $5 \times 5,5 \mathrm{~cm}$ boyutlarında heterojen kontrastlanan ve içerisinde çoğunlukla kistik alanların bulunduğu lezyon saptandı. Ancak, Amyand hernisi tanısını net olarak ortaya koymada yardımcı olamadı.

Amyand hernisi'nin nadir görülen bir klinik durum olmasından dolayı literatürde geniş seriler üzerinde yapılmış yeterli çalışma bulunmamaktadır. Bu nedenle, tedavi konusunda görüşbirliği oluşmamıştır. Tedavi modaliteleri herni kesesindeki apendiksin durumuna göre değişmektedir. Lasonof ve ark. $[13,14]$ apendiks normal ise sadece genç hastalarda apendektomi yapılabileceğini bunun dişında apendektomi yapılmadan apendiks vermiformisin redükte edilmesi gerektiğini savunurken, Ofili, Amyand hernisi bulunan 11 hastaya appendektomi uyguladığını; yara yeri enfeksiyonu veya nüks herni gibi komplikasyonlara rastlamadığını bildirmiş ve tüm Amyand hernilerinde apendektomi yapılması gerektiğini savunmuştur. Bizim olgumuz, Losanoff Amyand herni sınıflamasın da Tip 2'ye uymaktaydı (Tablo 1). Tedavisinde herni kesesi yoluyla apandektomi ve anatomik tamir uyguladık.

Tablo 1. Losanoff amyand herni siniflamasi; siniflama açiklama, tedavi yöntemi.

\begin{tabular}{lll}
\hline Sınıflama & Açılama & Tedavi \\
\hline Tip 1 & Normal apendiks & Redüksiyon; mesh ile fitık onarımı \\
Tip 2 & Akut apendisit; abdominal sepsis yok & F1tık kesesi yoluyla apendektomi; anatomik tamir \\
Tip 3 & Akut apendisit; abdominal sepsis var & Laparotomi yoluyla apendektomi; anatomik tamir \\
Tip 4 & $\begin{array}{l}\text { Akut apendisit; ilişkili ya da ilişkisiz } \\
\text { diğer karın patolojileri }\end{array}$ & Fitık kesesi ya da uygun laparotomi yoluyla apendektomi \\
& & \\
\hline
\end{tabular}

Sonuç olarak; bizim olgumuzda olduğu gibi, Amyand hernisi gibi komplike fitık nedeni ile yapılan ameliyatlarda tedavi stratejisi değiştirecek patolojiler görülebilir. Bu nedenle, özellikle ileri yaşta kasık fitığı tanısı ile ameliyat edilecek hastalarda, nadir görülen Amyand hernisi de akılda tutulmalı ve genel cerrahlar bu hastalığın tedavisi ve takibi konusunda bilgi sahibi olmalidırlar. 


\section{Kaynaklar}

1. 1.ÖztaşM, Yıldız R, Can MF. Amyand's Hernia; Case Series and Our Ten Years Experience. Journal of Surgical Arts 2013; 6: 1-3.

2. Burgess PL, Brockmeyer JR, Johnson EK. Amyand Hernia Repaired with Bio-A: A Case Report and Review. J Surg Education 2011; 68: 62-6.

3. Carey LC. Acute appendicitis occuring in hernias: A report of 10 cases. Surgery 1967; 31: 236-238.

4. Hutchinson R. Amyand's hernia. J R Soc Med 1993; 86: 104-5.

5. Priego P, Lobo E, Moreno I. Acute appendicitis in an incarcerated crural hernia: analysis of our experience. Rev Esp Enferm Dig 2005; 97: 707-5.

6. Losanoff JE, Basson MD. Amyand hernia: A classifica-tion to improve management. Hernia 2007; 12: 325-6.

7. Logan MT, Nottingham JM. Amyand's hernia: A case report of an incarcerated and perforated appendix withina an inguinal hernia and review of the literature. Am Surg 2000; 67: 628-9.

8. Ash L, Hatem S, Ramirez GA, Veniero J. Amyand's hernia: A case report of prospective CT diagnosis in the emergency department. Emerg Radiol 2005; 11: 231-2.

9. Maizlin ZV, Mason AC, Brown C, Brown JA. CT findings of normal and inflamed appendix in groin hernia. Emerg Radiol 2007; 14: 97-100.

10. Luchs JS, Halpern D, Katz DS. Amyand's hernia: Prospective CT diagnosis. J Comput Assist Tomogr 2000; 24: 884-6.

11. Weber RV HZ, Kraal JG. Amyand's hernia: Etiologic and therapeutic implicationsof the two complications. Surg Rounds 1999; 22: 552-6.

12. Anagnostopoulou S, Dimitroulis D, Troupis TG. Amyand's hernia: a case report. World J Gastroenterol 2006; 29: 4761-3.

13. Losanov JE, Basson MD. Amyand hernia: A classiWcation to improve management. Ofili OP: Simultaneous appendectomy and inguinal hernioraphy could be benefical. Ethiop Med J 1991; 29: 37-8.

14. Hazar E. Amyand Hernia: Case report.Cumhuriyet Med J 2013; 35: 597-9. 